\title{
DESIGNING AN ELEMENTARY COURSE OF ENGLISH FOR ADULTS AT COMMERCIAL ENGLISH SCHOOLS AND CENTERS IN UKRAINE ON THE BASIS OF THE COMMUNICATIVE-ANALYTIC METHOD
}

\author{
Oleg Tarnopolsky*
}

Golovposhtamt, abonentska skrynka 856, Dnipropetrovsk, 49000, Ukraine

Corresponding Email: otarnopolsky@mail.ru

Department of Applied Linguistics and Methods of Teaching Foreign Languages, Alfred Nobel University, Dnipropetrovsk, Ukraine

\begin{abstract}
Keywords: elementary course of oral everyday communication in English, teaching English to adults who learn it at commercial language schools and centers, communicative-analytic approach, equilibrium of communicative and language form-focused learning activities.
\end{abstract}

\begin{abstract}
The paper discusses a many-year-long experience of designing and using an elementary course of oral everyday communication when teaching English to adults who have previously finished an introductory (preparatory) course of that language and are principally oriented towards acquiring the skills of oral communication in English. The article is the continuation of the preceding article published in the International Letters of Social and Humanistic Sciences, and it discloses the way of practical implementation on the elementary level of language education of the communicative-analytic method substantiated in that previous paper. The elementary course analyzed in the article is created for the beginner's stage of learning English by those adults who desire to acquire it outside university language programs - for instance, in different kinds of commercial language schools and centers. The developed elementary course of oral everyday communication is structured on the basis of communicative-analytic approach with the equilibrium of communicative and language form-focused learning activities. Communicativeness is implemented by way of following Lewis's lexical approach and methods of intensive language teaching developed by Losanov. The course of 56 two-hour classes precedes the pre-intermediate course of speaking, listening, reading, and writing in English and follows a very short two monthlong introductory course.
\end{abstract}

\section{Introduction}

This article continues our publication in Vol. 65 of the International Letters of Social and Humanistic Sciences [1] that discussed the communicative-analytic method developed by us for teaching an English language program to adults at commercial language schools and centers. In that publication, the essence of the communicative-analytic method was disclosed and it was shown that the primary reason for developing it was the unwillingness and lack of psychological readiness of adult learners to learn the language in a purely communicate manner, their belief that communicative language learning must always be accompanied by language form-focused activities the share of which should the greater the lower the learners' level of English is. The communicative-analytic method was designed as a way out of the contradiction in which the target language has to be taught communicatively to attain every learner's goal of acquiring it for communicative purposes while, at the same time, most students believe that achieving that goal is impossible without the broad use of form-focused exercises which, in fact, do not teach communication but the language system only.

That contradiction was discussed by Nunan [2] and Green [3], and Nunan [2] suggested solving the problem by starting with focusing on language forms and then gradually introducing communicative learning activities and negotiating with students the transition to them until they finally almost totally oust the language form-focused activities. The communicative-analytic method developed by us is based on this recommendation. In our commercial English language 
program made of nine autonomous but interdependent and interconnected courses the first short (two month-long) preparatory introductory course of English pronunciation for total beginners is mostly based on analytic language form-focused learning activities with only one quarter of all learning activities being of communicative nature for developing learners' most elementary communicative skills, such as greeting, apologizing, thanking, introducing oneself, etc. It is by using just such activities that the teacher tries to demonstrate to students that learning through communication helps them achieve their communicative learning goals much faster and more efficiently than doing form-focused exercises. As a result of such teacher-learners' negotiation, an opportunity emerges in the next beginner's/elementary course of oral communication in English to increase substantially the share of communicative learning activities reducing considerably the share of form-focused ones. Such a tendency of increasing communication at the expense of language form-focusing continues and develops with every following course so that in the more advanced courses form-focused exercises, if not totally disappear, at least, are reduced to the barest minimum.

The aim of this article is to analyze the above-mentioned beginner's/elementary course of oral communication in English as the central one in the program in what concerns the practical implementation of the communicative-analytic method because it is in this course that the method is represented most demonstratively having the communicative and analytic form-focused learning activities in perfect equilibrium.

\section{The goal, structure, and content of the elementary course of oral communication in English}

The elementary course of oral communication in English was developed for the commercial English program taught at The Commercial Foreign Language Center (further called the Center) functioning on the premises and under the aegis of Alfred Nobel University, Dnipropetrovsk, Ukraine. This course is preceded, as it has already been said, by a two month-long (16 two hourlong classes two times a week, 32 academic hours in the course) preparatory introductory course that is, in fact, an organic initial part of the elementary course under consideration. But it is structurally separated from the elementary course because, as it also has been said already, one of the principal goals of the introductory course is psychologically preparing students for introducing in the former course a great number of communicative learning activities instead of the language form-focused ones to which they were accustomed in their preceding language learning experience.

The elementary course was designed for those adult learners who either just began learning English (beginners) or had been learning it some time ago, had not really acquired it then, and since that time had lost even the minimal skills developed earlier (false beginners).

The course is seven month-long with two 2-hour-long classes every week, i.e., 112 academic class hours in the course as a whole. The course is aimed exclusively at teaching everyday oral communication in English with reading and writing used only as supports for teaching and learning speaking and listening skills. The reasons for making the course only oral communication oriented were the results of potential and actual students' questionings that demonstrated the elementary level students' desire and need to acquire the skills of oral everyday communication in English first and only then proceed to developing their English reading and writing skills [4,5].

Following this potential and actual elementary students' need, the primary aim of the elementary course was formulated as training students in oral communication in English so as to allow them to be fully autonomous in solving all everyday tasks and problems that a person may encounter during a short-time (up to one month) stay abroad. This includes, for example, situations typical for a tourist trip or a short business trip: like passing the immigration and customs control, checking in at a hotel, eating out, shopping, etc. The learners, by the end of the course, are supposed to attain the command of speaking and listening skills in English in such situations on the level A2 according to the Common European Framework of Reference for Languages [6], while there is no clearly formulated level of skill attainment for reading and writing due to their purely supportive role in the course. 
Following this aim, the topics and situations of communications to be included into the teaching/learning process in the course were selected on the basis of questioning (in 1992) one hundred respondents in the city of Dnipropetrovsk who were making regular short-term trips abroad. They were given a list of 25 frequent communicative situations/communication topics typical of such trips and were asked to mark those that they believed to be the most important, i.e., encountered practically in all cases (they also had an opportunity of adding their own situations/topics). Those situations/topics that had been marked by 75 (75\%) of the respondents were included in the course. As a result of questioning, nine situations/topics were selected:

1. Meeting people, obtaining information about them, and giving personal information.

2. Passing immigration and customs checks when entering or leaving a foreign country.

3. Finding a place in town by asking for directions.

4. Using public transport.

5. Checking in at a hotel and checking out; using hotel services.

6. Eating out.

7. Different kinds of shopping.

8. Sightseeing, museum-, theatre-, cinema-, concert-going, other kinds of entertainment.

9. Traveling in and out of the country (purchasing tickets, getting information about the trip, etc.).

All the other learning content was selected according to these situations/topics (texts to be used in teaching/learning, language material, students' communicative skills to be developed, etc.). This content was collected and presented in the textbook "Nine Steps in London" [7] developed by us for the course. The most important part of every unit in the textbook are extensive dialogues/polylogues, each embodying and representing a typical conversation in one of the situations above and following a corresponding communication topic. All the sample dialogues/polylogues in the course are united by a single plot: two Ukrainians get acquainted on a plane flying to London. Both of them are traveling on business, and, as it happens, both have booked rooms in one and the same hotel. Having arrived in London, they pass together through the immigration and customs formalities, find the way to their hotel getting there by public transport, check in at the hotel, have their meals at a restaurant, and then spend their time in London together until one of them leaves for home.

Every such dialogue/polylogue contains quite a lot of new vocabulary for students and new grammar forms. Students' full understanding of the dialogue/polylogue, despite lexical and grammatical difficulties, is achieved thanks to the parallel translation of what is said in English into the students' native language (phrase for phrase). Such a translation is quite possible in the framework of the communicative-analytic method developed by us which allows the recourse to learners' mother tongue at the early stages of language acquisition when and where the mother tongue can help in and facilitate learning of the target language.

Both dialogues/polylogues in English and their parallel translations are represented in the graphic (printed) form at the beginning of every unit in the textbook, like in the example from the first unit below [7, pp. 15-16] (communicative situation/communication topic: "Meeting people, obtaining information about them, and giving personal information"): 
V.S. Sorry for interrupting, but I see you are reading a Ukrainian newspaper. Are you from Ukraine.

O.K. Sure I am. I am from Kyiv.

V.S. Oh, we are compatriots. Let me introduce myself. I am Vladimir Scherbak from Odessa.

O.K. Pleased to meet you. It's nice to meet a compatriot going abroad. My name is Olga Kravchenko.

V.S. Very glad to meet you too! Are you going on business or for pleasure? Maybe you are on a tourist trip?

O.K. Oh, no. I am going on a business trip. I am an economist and our organization has some contacts with a London company. And what about you?

V.S. Oh, I'm also on a business trip. I am a businessman. But are you going alone or with your colleagues? Maybe, someone from your family is accompanying you?

O.K. No, I am going alone. My family stays at home. And what about your family? Are you married?

V.S. Yes, I am married and have three children.

O.K. Three children! Oh, how wonderful! I believe, you are a lucky man. And how old are they?

V.S. The oldest boy is sixteen. His younger sister, she is twelve. And my youngest son, well, he is just six. And what about your family?

O.K. Well, I have a small family: I, my husband and our little daughter. She is just eight.

V.S. And what is your husband?

$\boldsymbol{O} . \boldsymbol{K}$. He is a mathematician.

Flight attendant. Drinks, please.

V.S. Let's have some drink. I am very thirsty.

O.K. Coca-cola is all right with me, thank you.

V.S. And orange juice for me, please.

Flight attendant. Here you are.

V.S. Thanks a lot.

O.K. Thank you very much. The coca-cola is very refreshing.

Flight attendant. I'm glad you like it.

The work in the classroom on every sample dialogue/polylogue begins with what is called its first processing.
Phrase for phrase translation into students' native language 


\section{The first processing - communicative-analytic part of the work on the sample dialogue/polylogue (synthesis 1)}

Every dialogue/polylogue is first heard by students in its audio recorded form as a reproduction of natural speech. Full understanding is achieved thanks to the parallel translation while learners are reading the graphic representation of the dialogue in their textbook at the same time as listening to it. Then, the teacher reads the dialogue making pauses all the time to explain new vocabulary and grammar, and this is the only analytic part in mostly communicative first processing. The next stage is students' reading the dialogue/polylogue aloud in pauses that speakers in the audio recording make. While reading aloud, students try to remember entire phrases that they pronounce as unities and not as sentences consisting of separate words. In this part of work Lewis's Lexical Approach is followed [8].

That approach continues to be followed in the next step of work on the sample dialogue/polylogue when students in pairs or in groups of three start dramatizing it. First, they simply role play the dialogue/polylogue by reading from the textbook in their pair or group work what has been said by every participant in the conversation - every student taking the role of one of the personages in it. But after reading the dialogue/polylogue one or two times, they close their textbooks and start speaking using the same phrases from memory (they are allowed "to peep into" the textbook if they forget something or the teacher may prompt them). This time learners already speak from and about themselves and not from and about the textbook characters. The tasks for such dramatizations make learners gradually move away from the dialogue/polylogue in the textbook creating their own dialogues/polylogues for similar situations - those reflecting their own life and not the lives of invented characters from the textbook.

Such dramatizations used during the first processing and well-known in language teaching literature and practice [9] have already been discussed in our preceding article [1] but some additional examples may be helpful (communicative situation/communication topic: "Checking in at a hotel and checking out; using hotel services")

A. Dramatize your contacts with a hotel receptionist (the partner in your pair) when checking in. You have not only booked your hotel room but pre-paid it and have a voucher to prove it.

B. Now do the same but the receptionist will inform you that there is no information about your reservation in his/her computer. Do not forget about your official voucher where there are all the telephones of your travelling agency that was doing the reservation and where the fact of reservation and payment can be confirmed.

C. Order breakfast to your room by phoning the hotel room service. Ask what they can offer and choose what you really like. But do not forget about the prices, ask about them, and if something is too expensive, think whether you can afford it, etc.

All such activities (the first processing) are planned for one and a half or two 2-hour classes out of five planned for working on one unit in the textbook. When students finish doing them, they are expected to operate more or less fluently with phrases from the sample dialogue/polylogue to communicate in similar situations. Since the material is acquired mostly synthetically as entire phrases to be reproduced in one's own communication this first processing is also called synthesis 1. However, there is an element of language forms analysis when the teacher explains some new forms when reading the sample dialogue/polylogue to students. This puts the first processing into the framework of our communicative-analytic approach though mostly it is designed following the precepts of organizing the first processing in intensive language teaching according to Losanov's approach [10]. Yet, the second processing in our system is absolutely unlike the latter approach, being totally analytic in its nature. 


\section{The second processing - analytic part of the work on the sample dialogue/polylogue (analysis)}

The second (analytic - language form-focused) processing is planned for two 2-hour classes out of five assigned for work on one unit from the textbook (it may be the second half of the second class, the entire third class, and the first half of the fourth class; or it may be the entire third and fourth classes). This processing, entirely devoted to language form analysis and analytical practicing of those forms, ensures: 1) an opportunity of concentrating learners' attention on new language phenomena introduced in the sample dialogue/polylogue and fully realize their meanings and forms through analysis which is quite important for adults [11];2) an opportunity of processing the language phenomena in the optimal way in the given context when learners are still on the very low level of language command and do not have whatever "natural" contacts with native speakers [12]; 3) an opportunity of working analytically on those language forms that the students have already actively used in their own speech during the first processing but before those forms will become totally separated from the sample dialogues/polylogues in freer communication during the third processing (see further). As a result, it becomes easier to transfer the acquired skills into communication which is not entirely based on the speech samples in sample dialogues/polylogues [4].

The second processing begins with more detailed explanations by the teacher of language phenomena from the sample dialogue/polylogue which he or she already much more summarily explained during the first processing (see above). The explanations are given as short instructions: when, for what, and how to use a certain language phenomenon and they follow the direction "from meaning to form" but never vice versa. The teacher's explanations are supported by grammatical and lexical commentaries in the textbook. The explanations are followed by two so-called laboratory works that continue until the end of the second processing stage/phase.

The first laboratory work is computerized (there is a printed version of it with keys for the conditions when the language school or center does not have adequate computer equipment). In fact, the course under consideration is the first in our program where CALL (computer assisted language learning) $[13,14]$ is introduced, and in every following course its importance and the place it occupies continue to grow.

In the computerized laboratory work the exercises are mostly traditional language formfocused ones, though the instructions to some of them may be communicatively "colored." Those instructions are given in students' mother tongue because understanding them in English may be too difficult for learners taking into account that students' work with computers is individual and autonomous. The teacher is always in the classroom when the laboratory work is being done and is always ready to help but explaining to students the instructions that might have been misunderstood because they were in English would take too much time.

Below are some examples of grammar-oriented exercises from the computerized language form-focused laboratory work (the instructions to exercises are translated into English):

1. An exercise for practicing the use of the verb 'to have' in Present Simple Tense. Instruction: You will see sentences where it is said that some person(s) want(s) to obtain some thing(s). Answer the statements by indicating in writing who has this (those) thing(s). Use the prompts. For instance, you see the sentence: 'I want to read books by Dickens in English' and the prompt: 'My friend.' You are required to type: 'My friend has books by Dickens in English.'

I want a glass - Prompt: the stewardess.

I want to see some good art collections - Prompt: Kyiv.

Our friend wants a new flat. - Prompt: $I$.

I want orange juice. - Prompt: We.

The tourists want to see old churches and monasteries. - Prompt: Chernighiv.

2. An exercise for practicing the use of disjunctive questions. Instruction: You will see sentences giving you some information about certain persons. For example: "I have a big 
apartment.' Having seen the sentence, type a disjunctive question to ask whether this information is also true for some other person(s). Use prompts. For instance, if the prompt is "Your brother," your typed question should be: "Your brother has a big apartment too, doesn't he?'

I am an engineer. - Prompt: your wife.

I have a private house. - Prompt: your friend.

I am going on a tourist trip. - Prompt: your son.

I often go on business trips - Prompt: your colleagues.

I have finished my work - Prompt: the other people at your office.

3. An exercise for practicing the use of Future Tenses (a purely formal exercise). Instruction: Open the brackets changing the Infinitive of the verb into Future Simple, Future Continuous, or Future Perfect depending on the meaning of the entire sentence.

We (to go) there tomorrow.

He (to find) his way already before you come to help him.

They (to stay) in this hotel for a fortnight.

He (to work) here for a month.

This bus (to take) you right there as quickly as possible.

I (to leave) by the time you're here.

Exercising with the use of the computer program under discussion is organized in the following manner. First, learners, working individually on their computers, get themselves familiarized with the instruction to this or that exercise. Then, immediately after the first sentence appears on the screen of the monitor, they type their answer to it. As soon as the answer is typed, if it is correct, loud applause is heard and the next sentence appears. If, on the contrary, the answer is wrong or giving an answer exceeded the three-minute time limit, a disappointed sigh sounds, on the screen the learners see: 'You have made a mistake! Try again,' and the sentence appears again for the learner to make a new attempt to answer correctly. If that attempt also fails, the rule about the use of the language phenomenon (which had been explained to students before they started doing the laboratory work - see above) is shown on the screen for the student to recapitulate it. After this, the third attempt to answer correctly follows, and only if that fails for the third time, the key (correct answer) is illuminated on the screen and the learner can proceed to working on the next sentence from the exercise. However, if, instead of the computer program, the printed version of exercises is used, such elaborate practicing, certainly, becomes impossible. Students write their answers and then check their correctness by printed keys, and that makes practicing less efficient. This is why practicing with a computer program is much more preferable.

The laboratory work done with the help of a computer program is always followed by another laboratory work done with the help of audio equipment. It, just like the preceding laboratory work, includes from 10 to 15 language form-focused (analytic) exercises, but, unlike the exercises in the previous laboratory work where only a part of instructions have communicative 'coloring,' (see the examples above), here all of them are communicatively 'colored.' Work on each of the exercises from the laboratory work is strictly individual - students individually work with the audio recorded practicing program in the classroom supervised by the teacher who is always ready to help when required. Practicing proceeds in the following manner.

First, a student listens to an audio recorded instruction to an exercise in English, at the same time reading that instruction in his/her mother tongue from the separate part of the textbook [7] that provides him/her with the printed version of the laboratory work. When the instruction is fully understood, the student presses the "Play" button and listens to the first stimulus-statement of the recorded speaker in the exercise. The learner is supposed to react to that statement as instructed using the provided prompts for his/her answer. The answer is given aloud by the student during the specially provided pause in the recording (imitation of a conversation with the recorded speaker). After the pause, the correct version of the expected answer is pronounced by another speaker in a lower voice than the initial stimulus-statement. It is given for the student to check himself/herself. If 
the student's answer was wrong, he/she is expected to repeat the correct version in the second pause. But if the answer was correct, the second pause is ignored. After that, the second stimulusstatement is pronounced by the speaker and so it goes until the end of the exercise. All the stimulistatements in every exercise and all the prompts for students to make correct answers are printed in the textbook after the instruction to every exercise, so that they are not only heard by learners but also read (visual graphic support). However, correct versions of students' answers for them to check themselves are only listened to without reading. Two typical exercises from two typical laboratory works are designed as shown below.

1. An exercise for practicing questions about the future. Instruction: Ask the speaker in order to get more specified information about what is going to happen. Since all your questions will concern the future, use the future tense form that corresponds to the meaning of your question which follows from the prompt provided. For instance, if you hear the speaker's statement: 'I will return home' and the prompt is 'by tomorrow,' you will need to use the Future Perfect Tense in your question: 'Will you have returned home by tomorrow?'. After putting your question, check yourself and listen to the speaker's answer.

The speaker's utterances: I will stay here.

The prompts:

for a few days (The expected student's question not supplied in the printed version of the exercise but given for self-checking after the pause for the question is 'Will you be staying here for a few days?'. The answer of the speaker, also not printed but only audio recorded, is 'I will be staying here for a week,' and similarly for all the following speaker's stimuli-statements in the exercise)

Pete will come to your place. When I will come to see you. We will ask him to do it. I will talk to my old friend by the end of the week Why when our annual meeting takes place

2. An exercise for practicing statements about actions completed by the moment of speaking (Present Perfect Tense). Instruction: Tell the speaker that you have already completed the actions that he is doing now.

The speaker's utterances:

I'm finishing my drink (the expected student's statement not supplied in the printed version of the exercise but given for self-checking after the pause for the answer is ' $I$ have already finished mine', and similarly for all the following speaker's stimulistatements in the exercise).

I'm paying my fare.

I'm revising for my exam.

I'm organizing a party.

I'm starting now.

After the second laboratory work is completed, the third processing begins.

\section{The third processing - communicative part of the work on the sample dialogue/polylogue (synthesis 2)}

This processing is purely communicative with no analytic (language form-focused) component in it. It takes from one two-hour class to one a half classes (three hours) which, together with the first two kinds of processing, makes those five classes that, as it has already been said, are planned for working on one unit in the textbook. 
The third processing is organized as a series of students' dramatizations performed in pairs or small groups of 3-4 students. Their difference from the dramatizations used in the first processing are in the problem-solving character of students' communicative tasks when dramatizing some situation of communication in the target language. It means that the task-based approach $[15,16,17]$ begins to be used in the third processing phase, and the dialogues/polylogues produced by learners move far enough from the sample dialogue/polylogue in the unit projecting students into the area of practically free target language communication though in a limited number of communicative situations and on the basis of limited language material planned for the elementary course. Problemsolving is what closely approaches dramatizations in the third processing to role plays $[18,19]$, and it is only their direct, though much weakened, connection with the sample dialogue/polylogue in each of the textbook units that makes us consider them as still belonging to dramatizations and not raising them to the higher level of role plays (which in our language program start to be used beginning with the pre-intermediate course).

Thus, the work in the third processing phase is totally synthetic and not analytic but this is a more advanced type of synthesis than in the first processing phase - the synthesis connected with problem-solving of which only initial traces can be noticed in synthesis 1 phase (see above the task for dramatization B in that phase). This is why the third processing is considered by us as synthesis 2 phase, as distinct from synthesis 1 in the first phase. Some examples of dramatization tasks in synthesis 2 phase are given below.

A. You are in London and you have hired a taxi to take you to Buckingham Palace which is a 10-minute drive from your hotel. Instead, the driver, who misheard you, has brought you to Kensington Palace that it is almost half an hour's drive away. Explain to the driver his mistake, ask him to take you where you really wanted to go and insist on paying only for the ride from your hotel to Buckingham Palace because it was the driver's fault, and you have lost time in addition. Be polite and try to come to an arrangement with the driver.

B. You have come to the theatre where you earlier bought tickets for the play you wanted to see. On coming to the theatre, you find out that the performance is put off until next Saturday and they insist on your simply exchanging your tickets and not giving you the full refund. But you are leaving before next Saturday and cannot see the play then. Talk to the administrator, explain the problem and try to solve it. Be polite at all times.

C. You have left your handbag (briefcase) on the seat of the city bus the number of which you remember. You are sure it was not stolen because there was nobody near you all through your ride and the bus was practically empty. It all happened five minutes ago. Go to the police station which is in front of you, explain the situation and ask them to get in touch with the bus driver so that he picks up and keeps the handbag (briefcase) for you.

Having done a series of such dramatization tasks (usually not less than twenty) students, as a rule, acquire sufficient skills for communicating freely and fluently enough in the framework of the topic and situations of communications that are planned to be processed in this or that unit of the textbook. It allows proceeding to the topic and communicative situations in the following unit, and then further on until the end of the course.

\section{Conclusion}

The beginner's/elementary course of English described in the paper precedes the preelementary course [20] in our commercial language program and follows a very short two monthlong introductory course [4]. The elementary course is based on three approaches, or general methods. The most important of them is the communicative-analytic method developed by us, discussed in some of our previous works (e.g., [1]), and mentioned, as the one fundamental for our language program, in the title of this article. In fact, the elementary course is the most representative of such a method in our entire commercial English language program. The representativeness of the course in what concerns our program is due to the fact that it is the only course in it where 
communicative and analytic (language form-focused) learning activities are fully balanced at the ratio of $50 \%$ to $50 \%$. That can be seen from the description above of the course design when work on every unit in the textbook begins with mostly communicative activities with some admixture of analytic ones (teacher's explanations of language phenomena in the sample dialogue/polylogue); this is followed by quite a considerable part of work devoted solely to analytic (language formfocused) explanations and exercises which are finally replaced by purely communicative learning activities. In the structure of the course such transitions are reflected in three principal stages, or phases of work on each of the sample dialogues/polylogues that make the key part of every unit: the first communicative-analytic processing of the dialogue/polylogue, its second analytic processing, and its third (final) communicative processing.

These three kinds of processing and the structure and design of the course as a whole with all learning activities in it also follow the guidelines of the Lexical Approach developed by Lewis [8] and of Losanov's approach to intensive language teaching [10]. First of all, it is the synthetic language learning implemented in the course (synthesis 1 and synthesis 2) when learners acquire new language not as separate units but as whole phrases on the basis of sample dialogues/polylogues and their dramatizations. Just such an approach is characteristic of the methods developed both by Lewis and Losanov.

Finally, the design of the course and, especially, topics and situations of communication selected for it provide very broad opportunities for ensuring the cultural orientation of students' language studies. What is meant here is not the culture with a big ' $\mathrm{C}$ ' (literature, art, laws, political systems, etc.) but the culture with a small 'c' - forms of behavior reflected in everyday communication and making it socially acceptable [21,22,23]. Just such cultural phenomena are very well covered by topics/situations of communication as "Meeting people," "Using public transport," "Eating out," and others constituting the communicative content of our elementary course. This coverage is broadly used to make students understand the cultural norms of communication typical of English-speaking countries [24].

The fact that all the various elements and methods indicated above are organically and harmoniously united in our elementary course is proved not only by our experimental study [4,25] but most of all by the success of the course in question with learners which makes it one of the most popular courses in our language program with greater numbers of students enrolled for it than in quite a lot of other courses. This is why the design and structure of the course described in this paper may be of interests to teachers of commercial English programs who teach beginner's/elementary courses in such programs irrespective of the country where those courses are taught.

\section{References}

[1] O. Tarnopolsky, Communicative analytic method in teaching English to adults at commercial language schools and centers in Ukraine, International Letters of Social and Humanistic Sciences. Vol. 65 (2015) 16-26. Access: www.scipress.com/ILSHS.65.16.

[2] D. Nunan, The Learner Centred Curriculum: A Study in the Second Language Learning, Cambridge University Press, Cambridge, 1988.

[3] J.M. Green, Student attitudes toward communicative and non-communicative activities: Do enjoyment and effectiveness go together? The Modern Language Journal. 77 (1993) 1-10.

[4] O. Tarnopolsky, Teaching English Intensively in a Non-English Speaking Country: Theory, Practice, and Results, ERIC Document Reproduction Service No. ED 428 579, 1999.

[5] O. Tarnopolsky, Writing English as a foreign language: A report from Ukraine, Journal of Second Language Writing. 9, No. 3 (2000) 209-226.

[6] Council of Europe, Common European Framework of Reference for Languages: Learning, Teaching and Assessment, Strasbourg, 2001.

[7] O. Tarnopolsky, Nine Steps in London, Dnipropetrovsk, 1993.

[8] M. Lewis, Implementing the Lexical Approach: Putting Theory into Practice, Thomson Heinle, 2002. 
[9] A. Maley, A. Duff, Drama Techniques in Language Learning: A Resource Book of Communication Activities for Language Teachers (Cambridge Handbooks for Language Teachers), Cambridge University Press, Cambridge, 1983.

[10] W.J. Bancroft, (1978). The Losanov method and its American adaptations, The Modern Language Journal, Vol. LXII, No.4 (1978) 167-175.

[11] S.S. Fotos, Integrating grammar instruction and communicative language teaching through grammar consciousness-raising tasks, TESOL Quarterly, 28 (1994) 323-351.

[12] J. McDonough, C. Shaw, Materials and Methods in ELT: A Teacher's Guide, Blackwell, Oxford, 1993.

[13] J.L. Egbert, Conducting research on CALL, in J.L. Egbert, \& G.M. Petrie (Eds.). CALL Research Perspectives, Lawrence Erlbaum, Mahwah, NJ (2005) 3-8.

[14] M. Warschauer, A developmental perspective on technology in language education, TESOL Quarterly, Vol.36, No.3 (2002) 458-474.

[15] N.S. Prabhu, Second Language Pedagogy, Oxford University Press, Oxford, 1987.

[16] T. Pica, (2007). Task-based instruction, in Nelleke van Deusen-Scholl and Nancy $H$. Hornberger (Eds.). Encyclopedia of Language and Education. Vol.4: Second and Foreign Language Education, Springer, New York, NY (2007) 71-82.

[17] P. Skehan, Plenary: Task-based instruction: Theory, research, practice, in A. Pulverness (Ed.). IATEFL 2002. York Conference Selections, IATEFL, Whitstable, Kent (2002) 90-99.

[18] M. Livingstone, Role Play in Language Learning, Longman, London, 1982.

[19] M. van Ments, The Effective Use of Role Play: A Handbook for Teachers and Trainers, Kogan Page, London, 1999.

[20] O. Tarnopolsky, Combining communicative-analytic and experiential approaches in teaching pre-intermediate level of General English to adults at commercial language schools and centers, World Scientific News. Vol. 36, (2016) 109-126. Access: www.worldscientificnews.com

[21] J. Corbett, 'Chewing the fat' is a cultural issue, IATEFL Issues, No. 148 (1999) 2-3.

[22] D. Killick, Culture and capability. Crossing the divide, IATEFL Issues, No. 148 (1999) 4-7.

[23] O. Tarnopolsky, Teaching etiquette communicative behavioral patterns to students of English as a foreign language, Atlantis, Vol. XXIII, Num. 2 (2001) 105-117.

[24] M. Byram, Teaching and Assessing Intercultural Communicative Competence, Multilingual Matters, Clevedon, 1997.

[25] O.B. Tarnopolsky, Intensive immersion ESP teaching in the Ukraine: Theoretical foundations and practical results, in Joaquim Arnau, Josep M. Artigal (Eds.). Immersion Programmes: A European Perspective, Publicacions de la Universitat de Barcelona (1998) 675-684. 